\title{
Self-Efficacy as a Predictor of High School Students' Subjective Well-Being*
}

\author{
Bülent Baki TELEF ${ }^{* *}$ Enes ERGÜN ${ }^{* * *}$
}

Received: 13 July 2013

Accepted: 05 June 2013

\begin{abstract}
The purpose of this study is to determine whether subjective well-being of high school students is predicted by their academic, social, and emotional self-efficacy. The sample of this study consisted of 311 high school students of whom 64\% $(n=199)$ were girls and 36\% $(n=112)$ were boys. Data were collected by the SelfEfficacy Scale for Children, the Positive and Negative Experience Scale, and the Life Satisfaction Scale and analyzed through multiple regression analysis. Results showed that high school students' academic, social, and emotional selfefficacy explained $19 \%$ of variance in their subjective well-being and predicted their subjective well-being. Activities performed by school counselors to increase students' academic, social, and emotional self-efficacy levels are thought to contribute to their subjective well-being.
\end{abstract}

Keywords: academic self-efficacy, social self-efficacy, emotional self-efficacy, subjective well-being

\section{Extended Abstract}

Purpose and Significance: Subjective well-being includes emotional reactions, areas of satisfaction, and general statements on life satisfaction of an individual (Diener, Suh, Lucas, \& Smith, 1999). It has a multidimensional structure both in adolescents and in adults (Huebner \& Dev, 1996; Long, Huebner, Wedell, \& Hills, 2012). According to Garcia, Rosenberg, Erlandsson, and Siddiqui (2010), happy adolescents have positive emotions and are more satisfied with their lives. Self-efficacy is defined as "people's judgments of their capabilities to organize and execute courses of action required to attain designated types of performances” (Bandura, 1986: 396). Self-efficacy beliefs have a positive effect on both positive thinking, namely, positive view of self and life, and on positive expectations of adolescents (Caprara, Steca, Gerbino, Paciello, \& Vecchio, 2006). People with high-level self-efficacy are more interested in well-beingrelated stimuli whereas low-level self-efficacious people are interested in threat-related stimuli (Karademas, Kafetsios, \& Sideridis, 2007). According to Singh and Udainiya (2009), high-level self-efficacy can enhance well-being in several ways. High selfefficacy contributes to high-level life satisfaction and engagement. In addition to the fact that mastery experiences are the primary source of self-efficacy, positive role models, precise understanding of physical and emotional feelings and positive feedback also support self-efficacy. Suggesting some models to develop effective interventional and organizational techniques to improve personal development and well-being, Caprara et al. (2006) said social-cognitive theory highlights sources and mechanisms

\footnotetext{
* Paper presented in the International Psychological Counseling and Education Conference.

**A Assist. Prof. Dr., Çanakkale Onsekiz Mart University, Çanakkale, Turkey, bakitelef@gmail.com

**** Res. Assist., Çanakkale Onsekiz Mart University, Çanakkale, Turkey, enes.ergun@boun.edu.tr
} 
through which self-efficacy beliefs affect behavior. This study is of great significance, making contribution to understand how self-efficacy affects subjective well-being. The purpose of this study is to determine whether subjective well-being of high school students is predicted by their academic, social, and emotional self-efficacy.

Methods: This study had a descriptive design. The sample of the study consisted of 311 high school students of whom $64 \%(n=199)$ were girls and $36 \%(n=112)$ were boys. Among all, 100 (32,2\%) were freshmen, 75 (24,1\%) were sophomores, 88 (28,3\%) were juniors and $48(15,4 \%)$ were seniors. Were 224 (72\%) of the participants from Anatolian high schools and 87 (28,0\%) were from vocational high schools. Data were collected by means of the three scales: the Self-Efficacy Scale for Children (Muris, 2001; Telef, 2011), the Positive and Negative Experience Scale (Diener, Wirtz, Tov, Kim-Prieto, Choi, Oishi, \& Biswas-Diener, 2010; Telef, 2011, 2013), and the Life Satisfaction Scale (Diener, Emmons, Larsen, \& Griffin, 1985; Köker, 1991). Data were analyzed through multiple linear regression analysis.

Results: Results showed that high school students' academic, social, and emotional selfefficacy explained $19 \%$ of variance in their subjective well-being. Respectively, emotional self-efficacy $(\beta=.21, p<.01)$, academic self-efficacy $(\beta=.21, p<.01)$, and social self-efficacy $(\beta=.16, p<.01)$ predicted subjective well-being.

Discussion and Conclusion: Results showed that academic self-efficacy, social selfefficacy, and emotional self-efficacy are significant predictors of subjective well-being. Likewise, in similar studies, subjective well-being and self-efficacy has been found positively correlated (Bergman \& Scott, 2001; Caprara, Steca, Gerbino, Paciello, \& Vecchio, 2006; Cicognani, Albanesi, \& Zani, 2008; Magaletta \& Oliver, 1999; Natvig, Albrektsen, \& Qvarnstrøm, 2003; Strobel, Tumasjan, \& Sporrle, 2011; Tong \& Song, 2004). Within this context, it can be concluded that subjective well-being will improve if academic, social, and emotional self-efficacy of high school students are enhanced. High school students who feel academically competent, socially skillful, and can cope with negative emotions can be regarded as happier individuals. As a result, activities performed by school counselors to increase students' academic, social, and emotional self-efficacy levels are thought to contribute to their subjective well-being. 


\title{
Lise Öğrencilerinin Öznel İyi Oluşlarının Yordayıcısı Olarak Öz-Yeterlik*
}

\author{
Bülent Baki TELEF ${ }^{* *} \quad$ Enes ERGÜN ${ }^{* * *}$
}

Makale Gönderme Tarihi: 13 Temmuz 2013

Makale Kabul Tarihi: 05 Haziran 2013

ÖZET: Bu araştırmanın amacı, lise öğrencilerinin akademik, sosyal ve duygusal öz-yeterliklerinin öznel iyi oluşu yordayıp yordamadığını belirlemektir. Araştırmanın çalışma grubunu, farklı liselerde öğrenim gören 311 öğrenci oluşturmaktadır. Katılımcıların \%64'ü $(n=199)$ kız, \%36'sı $(n=112)$ erkektir. Araştırma verileri, Çocuklar İcin ÖzYeterlik Ölçeği, Olumlu ve Olumsuz Yaşantı Ölçeği ve Yaşam Doyumu Ölçeği ile toplanmıştır. Araştırmadan elde edilen verilerin analizinde çoklu doğrusal regresyon analizi kullanılmıştır. Yapılan çoklu doğrusal regresyon analizi sonucunda akademik, sosyal ve duygusal öz-yeterlik, öznel iyi oluşun \%19'unu açıklamaktadır. Sonuç olarak, akademik, sosyal ve duygusal öz-yeterliğin lise öğrencilerinin öznel iyi oluşlarını yordadığı saptanmıştır. Okul psikolojik danışmanlarının akademik, sosyal ve duygusal öz-yeterliği artırmaya yönelik yapacakları çalışmaların, öğrencilerin öznel iyi oluşlarının gelişimine olumlu katkı sağlayacağı düşünülmektedir.

Anahtar Kelimeler: akademik öz-yeterlik, sosyal öz-yeterlik, duygusal öz-yeterlik, öznel iyi oluş.

\section{Giriş}

İnsan ve yaşam bilimleri ile ilgilenen araştırmacı ve teorisyenler öznel iyi oluş üzerinde etkisi olan faktörleri ve kaynakları ortaya koymayı denemişlerdir. Bu amaçla kültürel, dini, ekonomik, sosyal, fiziksel ve psikolojik faktörler tartışılmıştır (Pasadashi, Dehnavi, \& Botlani, 2012). Öznel iyi oluş, kişinin duygusal tepkilerini, doyum alanlarını ve yaşam doyumu ile ilgili yargılarını içermektedir (Diener, Suh, Lucas, \& Smith, 1999). Kavramsal olarak, iyi oluş ögelerinin her biri, kişinin yaşamının farklı yollarla değerlendirilmesini yansitır. Olumlu ve olumsuz duygular, kişinin yaşamındaki iyi ve kötü koşulları anlık ve hemen yansıtır. Bazı alanlardaki doyumlar ise kişinin yaşamındaki özel ögelerin bilişsel değerlendirmesini yansıtır. Yaşam doyumu genel yargıları yansıtır, fakat bütün olarak kişinin yaşamındaki doyum hakkında yararlı bilgi sağlar (Diener, Scollon, \& Lucas, 2004). Öznel iyi oluşun ergenlerde de yetişkinlerde olduğu gibi çok boyutlu bir yapı olduğu saptanmıştır (Huebner \& Dev, 1996; Long, Huebner, Wedell, \& Hills, 2012). Mutlu bir ergenin, yaşamdan daha fazla doyum aldığı ve olumsuz duygulardan çok olumlu duygular yaşadığı varsayılmaktadır (Garcia, Rosenberg, Erlandsson, \& Siddiqui, 2010). Eryılmaz (2012)'ye göre ergenler, olumsuz olay ve durumlara karşı mesafe koyma, kontrollü ilişki kurma, iyimser düşünme, olumlu zaman yöneliminde bulunma, doğrudan mutluluğa yönelik davranışlar sergilemeyi isteme, sorunları çözme ve dini inanca sığınma aracılığıyla öznel iyi oluşlarını korumaktadırlar. Araş̧ırmalarda benlik saygısı (Çevik, 2010; Karatzias, Chouliara, Power, \& Vivien, 2006), sosyal destek (Çevik, 2010), algılanan kontrol (Eryılmaz \& Ercan, 2010) ve duygusal zekânın (Çelik, 2008) ergenlerde öznel iyi oluşun önemli yordayıcıs1 olduğu bulunmuştur. Birçok araştırma, ergenlerin yaşamış olduğu anksiyeteye, depresyona, stresörlere, yetersizliklere ve zararlı davranışlara

\footnotetext{
* Bu makale, Uluslararası Psikolojik Danışma ve Eğitim Kongresinde sözlü bildiri olarak sunulmuştur.

${ }^{* *}$ Yrd. Doç. Dr., Çanakkale Onsekiz Mart Üniversitesi, bakitelef@gmail.com

****Arş. Gör., Çanakkale Onsekiz Mart Üniversitesi, enes.ergun@boun.edu.tr
} 
odaklanmıştır. Oysaki ergenlerin yaşamlarındaki pozitif ögelere daha fazla önem vermek, ergenlerin gelişim sürecinde daha iyi anlaşılmasına katkıda bulunabilir (BenZur, 2003).

Öz-yeterlik, "İnsanların belirlemiş oldukları performansı elde etmek için gerekli olan eylemi gerçekleştirme ve organize etme kapasitesi ile ilgili yargıları" olarak tanımlanmıştır (Bandura, 1986: 396). Sosyal bilişsel teoriye göre öz-yeterlik inançları, insanların motivasyonunun, mutluluğunun ve kişisel başarılarının temelidir. Kişiler arzu ettikleri sonuçlara ulaşabileceklerine ve eylemleri ile istemedikleri şeyleri engelleyebileceklerine inanmadıkça, sıkıntı ve zorluklara karşı sebat etmek ve eylemde bulunmak için çok az güdüye sahip olurlar. Öz-yeterlik inançları, diğer faktörler ne olursa olsun, kişileri motive ederek ve onlara rehberlik ederek, yaşam koşullarını ve işlevlerini güçlü şekilde etkiler (Bandura, Caprara, Barbaranelli, Pastorelli, \& Regalia, 2001). Öz-yeterlik inançları, davranışın en önemli belirleyicileri arasındadır. Eğer kişi kapasitesine inanmiyorsa, eylemde bulunmayı sağlayan dürtü azalır. İnsan fonksiyonunun önemli boyutlarını içeren fiziksel ve ruhsal sağlık sonuçları ile yeterlik inançları arasında kuvvetli bir bağ olduğu birçok araştırmada vurgulanmıştır (Maddux, 2002). Öz-yeterlik inançları, duyguların hem yoğunluğunu hem de tipini etkiler. Amaçları elde etmeye yönelik düşük öz-yeterlik, umutsuzluğa neden olur. Negatif duygusal durum sonucunda ortaya çıkan rahatsız edici düşünceleri kontrol etme inancindan yoksunluk, zayıf öz-yeterliğe, düşük performansa ve daha fazla ümitsizliğe neden olur. Pozitif duygusal durum ise öz-yeterliği artırır (Marat, 2003). Gupta ve Kumar (2010)'a göre duygular, öz-yeterliği etkilemektedir. Olumlu duygular özyeterliği artırmakta, olumsuz ya da karamsar duygular ise öz-yeterliği azaltmaktadır. Öz-yeterlik inançları, hem ergenin pozitif düşünmesinde, yani kendisi ve yaşamı ile ilgili olumlu görüşlerinde, hem de gelecek hakkında olumlu beklentilerinde pozitif etkiye sahiptir (Caprara, Steca, Gerbino, Paciello, \& Vecchio, 2006). Yüksek öz-yeterlik sergileyen kişiler iyi olmaya yönelik uyaranlara eğilimliyken, düşük öz-yeterlik sergileyen kişiler tehdit ile ilgili uyaranlara eğilimlidirler (Karademas, Kafetsios, \& Sideridis, 2007). Öz-yeterliğin pozitif psikoloji üzerinde dolaylı etkisinin olabileceği ileri sürülmüştür (Khodarahimi, 2010). Singh ve Udainiya (2009)’a göre güçlü özyeterlik, kişinin iyi olmasını birkaç yolla artırabilir. Yüksek öz-yeterlik, yüksek seviyede yaşam doyumuna ve uğraşlara katkıda bulunur. Doğrudan yaşantılar, özyeterliğin arkasındaki en önemli güçtür. Olumlu rol modelleri, fiziksel ve duygusal hisleri doğru okuma ve olumlu geri bildirimler iyi oluşa katkıda bulunur. Sosyal-bilişsel teori, öz-yeterlik inançlarının kaynağına ve davranışları etkileme mekanizmalarına dikkat çeker. Uygun öz-yeterlik inançları, bireysel gelişim ve iyi oluşu yükseltmede kullanılacak etkili müdahale ve düzenleme yöntemleri geliştirmek için çeşitli modeller önerir (Caprara ve diğerleri, 2006). Uluslararası literatürde öz-yeterliğin öznel iyi oluş ile ilişkisini ortaya koyan çalışmalar bulunmasına rağmen ulusal düzeyde bir çalışmaya rastlanmamıştır. Araştırma, ulusal düzeyde öznel iyi oluş üzerinde öz-yeterliğin etkisinin anlaşılmasına katkı sağlanması açısından önemlidir. Bu çalışmada, akademik, sosyal ve duygusal öz-yeterliğin öznel iyi oluşu yordayıp yordamadığı araştırılmıştır. 


\section{Yöntem}

Betimsel yönteme sahip bu araştırmanın çalışma grubunu, farklı liselerde öğrenim gören 311 öğrenci oluşturmaktadır. Katılımcıların \%64’ü (n=199) kız, \%36's1 $(n=112)$ erkektir. Öğrencilerin 100'ü (\%32.2) 9. sınıf, 75'i (\%24.1) 10. sinıf, 88'i (\%28.3) 11. sınıf, 48’i (\%15.4) 12. sınıf öğrencisidir. Araştırmada 224 (\%72) öğrenci, Anadolu liselerinde ve 87 (\%28) öğrenci ise meslek liselerinde öğrenim görmektedir.

\section{Veri Toplama Araçları}

Araştırmanın verileri, Çocuklar İçin Öz-Yeterlik Ölçeği, Olumlu ve Olumsuz Yaşantı Ölçeği, Yaşam Doyumu Ölçeği ve Kişisel Bilgi Formu ile toplanmıştır.

Çocuklar için öz-yeterlik ölçeği. Çocuklar İçin Öz-Yeterlik Ölçeği, Muris (2001) tarafından 12-19 yaşlarındaki ergenlerin sosyal, akademik ve duygusal özyeterliklerini ölçmek amacı ile geliştirilmiştir. Toplam 21 maddeden oluşan ölçeğin her alt boyutunda yedişer madde bulunmaktadır. Çocuklar İçin Öz-Yeterlik Ölçeği, 5'li Likert tipi ( 1 = hiç ve 5 = çok iyi) bir ölçektir. Toplam öz-yeterlik, her alt faktör ile ilgili maddelerden alınan puanlar toplanarak hesaplanır. Ölçekten alınabilecek en yüksek puan 105, en düşük puan ise 21'dir. Ölçek, Telef (2011) tarafından Türkçeye uyarlanmıştır. Doğrulayıcı faktör analizinde uyum indeksi değerleri RMSEA=.04, $\mathrm{NFI}=.95$, CFI=.96, GFI=.94 ve SRMR=.06 olarak bulunmuştur. Ölçeğin ölçüt bağımlı geçerliğini belirlemek için Genel Öz-Yeterlik Ölçeği kullanılmıştır. İki ölçeğin uygulanmasından elde edilen puanlar arasında Pearson Momentler Çarpımı Korelâsyonu .57 $(p<.01)$ olarak bulunmuştur. Çocuklar İçin Öz-Yeterlik Ölçeğinin iç tutarlık katsayıları, ölçeğin geneli için .86, alt boyutları olan akademik öz-yeterlik için .84, sosyal öz-yeterlik için .64, duygusal öz-yeterlik için .78 olarak hesaplanmıştır. Ölçeğin test-tekrar test güvenirlik katsayılarının ise .75 ile .89 arasında değiştiği görülmüştür. Ölçekten alınan yüksek puan, ergenin öz-yeterlik düzeyinin yüksek olduğuna; ölçekten alınan düşük puan ise ergenin öz-yeterlik düzeyinin düşük olduğuna işaret etmektedir (Telef, 2011).

Öznel iyi oluşun ölçülmesi. Kuramsal olarak öznel iyi oluş çok boyutlu bir yap1 olarak ele alınmış ve öznel iyi oluşun olumlu duygular, olumsuz duygular ve yaşam doyumundan oluştuğu ifade edilmiştir (Diener, 1984; Diener, Suh, Lucas, \& Smith, 1999). Son yıllarda Diener ve diğerleri (2010), olumlu ve olumsuz duyguları olumlu ve olumsuz yaşantılar olarak değerlendirmişlerdir. Öznel iyi oluş puanı hesaplanırken birçok araştırmacı

\section{Öznel iyi oluş $=($ Olumlu duygu + Yaşam doyumu $)-$ Olumsuz duygu}

formülünü kullanmıştır (Atak, 2011; Cenkseven \& Akbaş, 2007; Eryılmaz, 2010; Eryılmaz \& Öğ̈̈lmüş, 2010; Huebner \& Dev, 1996). Bu araştırmada öznel iyi oluş puanı, bu formüle dayalı olarak elde edilmiştir. 
Olumlu ve olumsuz yaşantı ölçeği. Olumlu ve Olumsuz Yaşantı Ölçeği, olumlu ve olumsuz duyguları ve iyi oluşu ölçmek için Diener ve diğerleri (2010) tarafından geliştirilmiş kısa bir ölçektir. Ölçeğin üniversite öğrencileri ile Türkçeye uyarlama çalışması Telef (2011) tarafından yapılmıştır. Ergen örneklemi ile Telef (2013) tarafından yapılan geçerlik ve güvenirlik çalışması sonucunda ölçeğin, orijinalinde ve üniversite öğrencileri ile yapılan uyarlama çalışmasında olduğu gibi iki faktörden oluştuğu, olumlu yaşantı boyutunun varyansın \%33.31'ini, olumsuz yaşantı boyutunun varyansın \%26.70'ini açıkladığı saptanmıştır. Ölçek maddelerinin faktör yükleri, .60 ile .86 arasında hesaplanmıştır. Doğrulayıcı faktör analizinde uyum indeksi değerleri $\mathrm{RMSEA}=.07, \mathrm{SRMR}=.04, \mathrm{GFI}=.93, \mathrm{NFI}=.96, \mathrm{RFI}=.95, \mathrm{CFI}=.97$ ve $\mathrm{IFI}=.97$ olarak bulunmuştur. Ölçeğin güvenirlik çalışmasında Cronbach alfa katsayısı, olumlu yaşantı boyutu için .88 ve olumsuz yaşantı boyutu için .83 olarak hesaplanmıştır. Olumlu ve Olumsuz Yaşantı Ölçeğinin her bir maddesi, 1-5 aralığında puanlanmakta ve 1, "Çok nadir ya da hiçbir zaman”, 5, "Çok sık ya da her zaman” şeklinde ifade edilmektedir. Ölçek, bağımsız ya da ayrı iki tip duyguyu ölçtüğünden ayrı ayrı puanlanır. Olumlu ve olumsuz puanların toplamı, 6 ile 30 arasında değişmektedir.

Yaşam doyumu ölçeği. Yaşam Doyumu Ölçeği, genel yaşam doyumunu ölçmek için Diener, Emmons, Larsen ve Griffin (1985) tarafından geliştirilmiş, Köker (1991) tarafından Türkçeye uyarlanmıştır. Ölçek, "hiç uygun değil” (1) ile "tamamıyla uygun" (7) arasında değişen Likert tipinde 5 maddeden oluşan bir kendini değerlendirme ölçeğidir. Köker (1991), ölçeğin üç hafta arayla uygulanan test-tekrar test tutarlık katsayısının $r=.85$, madde-test korelasyonlarının ise $r=.71$ ile $r=.80$ arasında olduğunu belirlemiştir. Ölçeğin Cronbach alfa iç tutarlık katsayısı $(\alpha)$.76'dır. Ölçekten alınan puan, 5 ile 35 arasında değişmektedir.

Kişisel bilgi formu. Kişisel Bilgi Formu, öğrencilerin cinsiyet, yaş, sınıf ve öğrenim gördükleri lise türünü belirlemek için araştırmacı tarafından hazırlanmıştır.

\section{Verilerin Analizi}

Verilerin analizinde çoklu doğrusal regresyon analizi kullanılmıştır. Araştırmanın istatistiksel analizleri, SPSS 16.0 paket programı kullanılarak yapılmıştır.

\section{Bulgular}

Lise öğrencilerinin akademik, sosyal ve duygusal öz-yeterliklerinin öznel iyi oluşu yordamasına ilişkin çoklu regresyon analizi sonuçları Tablo 1'de sunulmuştur. 
Tablo 1

Akademik, Sosyal ve Duygusal Öz-Yeterliğin Öznel İyi Oluşu Yordamasına İlişkin Regresyon Analizi Sonuçları

\begin{tabular}{lccccc}
\hline Değişken & $B$ & $\begin{array}{c}\text { Standart } \\
\text { Hata }\end{array}$ & $\beta$ & $t$ & $p$ \\
\hline Sabit & 5.088 & 3.554 & - & 1.432 & .15 \\
Akademik Öz-yeterlik & .448 & .118 & .213 & 3.812 & $.00^{*}$ \\
Sosyal Öz-yeterlik & .367 & .138 & .156 & 2.665 & $.00^{*}$ \\
Duygusal Öz-yeterlik & .412 & .117 & .207 & 3.523 & $.00^{*}$
\end{tabular}

$R=0.44, R^{2}=.19, F_{(3,307)}=24.64, p=.00$

Tablo 1 incelendiğinde akademik, sosyal ve duygusal öz-yeterliğin, öznel iyi oluşu anlamlı düzeyde yordadığı görülmektedir $\left(R=44, R^{2}=.19 p<.01\right)$. Standardize edilmiş regresyon katsayısına $(\beta)$ göre yordayıcı değişkenlerin öznel iyi oluş üzerindeki göreli önem sırası, akademik öz-yeterlik $(\beta=.21, p<.01)$, duygusal öz-yeterlik $(\beta=.21$, $p<.01)$ ve sosyal öz-yeterlik $(\beta=.16, p<.01)$ şeklindedir. Regresyon katsayılarının anlamlılığına ilişkin $t$ testi sonuçları incelendiğinde duygusal, akademik ve sosyal özyeterliğin öznel iyi oluşun önemli bir yordayıcısı olduğu saptanmıştır. Akademik, sosyal ve duygusal öz-yeterlik, öznel iyi oluşun \%19’unu açıklamaktadır.

\section{Sonuç ve Tartışma}

$\mathrm{Bu}$ araştırmanın amacı, lise öğrencilerinin öznel iyi oluşları ile öz-yeterlikleri arasındaki ilişkileri incelemektir. Araştırmanın sonuçları, akademik, sosyal ve duygusal öz-yeterliğin öznel iyi oluşun önemli bir yordayıcısı olduğunu göstermektedir. Bu bulgular doğrultusunda lise öğrencilerinin akademik, sosyal ve duygusal öz-yeterlikleri arttıkça öznel iyi oluşlarının da arttığı söylenebilir.

Literatürdeki araştırma sonuçları incelendiğinde öznel iyi oluş ile öz-yeterlik arasında pozitif yönde anlamlı ilişkiler olduğu belirlenmiştir (Bergman \& Scott, 2001; Caprara, Steca, Gerbino, Paciello, \& Vecchio, 2006; Cicognani, Albanesi, \& Zani, 2008; Magaletta \& Oliver, 1999; Natvig, Albrektsen, \& Qvarnstrøm, 2003; Strobel, Tumasjan, \& Sporrle, 2011; Tong \& Song, 2004). İkiz ve Telef (2013) ortaokul öğrencileri ile yapmış oldukları çalışmada akademik, sosyal ve duygusal öz-yeterliğin yaşam doyumunun önemli bir yordayıcısı olduğunu bulmuşlardır. Cicognani, Albanesi ve Zani (2008)'e göre kişisel bir kaynak olan öz-yeterlik, iyi oluşu doğrudan artırmaktadır. Khodarahimi (2010) ise öz-yeterlik gibi pozitif öznel deneyimlerin kişinin performansında hayati öneme sahip olduğunu belirtmiştir çünkü insanın olumlu duyguları, fenomenolojik algılardır. Dolayısıyla bu duygular, öznel iyi oluşu artırırken ruhsal rahatsızlıklar ve endişe gibi patolojileri düşürmektedir. Bergman ve Scott (2001), ergenlerin mutsuzlukları arttıkça olumsuz öz-yeterliklerinin arttığını belirtmiş̧lerdir. Suldo ve Huebner (2006)’a göre ise ergenlerin olumsuz duygular ile başa çıkma algısı 
arttıkça mutlulukları da artmaktadır. Gupta ve Kumar (2010), yüksek duygusal özyeterliğin iyi ruh sağlığını sürdürmede çok önemli olabileceğini ifade etmişlerdir. Ergenler, olumsuz duygular ile başa çıkma yeterliğine sahip olduğunda kendisine olan güveni artacak ve olumsuz duyguların üstesinden daha kolay gelebilecektir (Willemse, 2008).

Caprara ve diğerleri (2006), ergenlerin iyilik halini, olumlu düşünmeyi ve mutluluğun belirleyicisi olarak öz-yeterliği inceledikleri çalışmalarında olumlu ve olumsuz duyguları yönetmenin, öz-yeterlik inançlarının ve sosyal öz-yeterliğin ergenlerin gelecek hakkında olumlu beklentiler geliştirmelerine katkıda bulunduğunu saptamışlardır. Holder ve Coleman (2009)'a göre sosyal ilişkiler, mutluluğun önemli bir yordayıcısıdır. Özbay ve diğerleri (2012), üniversite öğrencilerinin öznel iyi oluşlarını yordayan değişkenleri inceledikleri çalışmalarında sosyal öz-yeterliğin öznel iyi oluşun önemli bir yordayıcısı olduğunu belirtmişlerdir. Canbay (2010), lise öğrencilerinin sosyal becerileri arttıkça öznel iyi oluşlarının da arttığını bulmuştur. Çevik (2010)'e göre ergenin akranları ile ilişkileri, onun yaşamında önemli bir yere sahiptir. Yakın arkadaşlık kurabilen, kurduğu arkadaşlık ilişkisini sağlıklı bir biçimde sürdürebilen sosyal çevresi geniş bir ergen, yalnızlık, uyumsuzluk gibi olumsuz duygular yaşamayacak, aksine sosyal becerisi yüksek, girişken, kendine güvenen, mutlu bir birey olacaktır.

Sonuç olarak, akademik olarak kendini yeterli hisseden, olumsuz duygular ile başa çıkabilen ve sosyal ilişkilerinde yeterli olan lise öğrencilerinin daha mutlu olduğu söylenebilir. Okul psikolojik danışmanlarının akademik, sosyal ve duygusal öz-yeterliği artırmaya yönelik yapacakları çalışmaların öğrencilerin öznel iyi oluşlarının gelişimine olumlu katkı sağlayacağı düşünülmektedir.

\section{Kaynakça}

Atak, H. (2011). Yetişkinliğe geçiş yıllarında sigara içme davranışının psiko-sosyal belirleyicileri ve sigara içmenin yaşam doyumu yaşam doyumu ve öznel iyi oluş ilişkisi. Klinik Psikiyatri, 14, 29-43.

Bandura, A. (1986). Social foundations of thought and action: A social cognitive theory. Englewood Cliffs, NJ: Prentice-Hall.

Bandura, A., Caprara, G. V., Barbaranelli, C., Pastorelli, C., \& Regalia, C. (2001). Socio-cognitive self-regulatory mechanisms governing transgressive behavior. Journal of Personality and Social Psychology, 80, 125-135.

Ben-Zur, H. (2003). Happy adolescents: The link between subjective well-being, internal resources and parental factors. Journal of Youth and Adolescence, 32, 6779.

Bergman, M. M., \& Scott, J. (2001). Young adolescents' well-being and health-risk behaviors: Gender and socio-economic differences. Journal of Adolescence, 24, 183-197. 
Canbay, H. (2010). Lise öğrencilerinin öznel iyi oluş düzeyleri ile sosyal beceri düzeyleri arasındaki ilişkinin incelenmesi (Yayımlanmamış yüksek lisans tezi). Dokuz Eylül Üniversitesi, İzmir.

Caprara, G. V., Steca, P., Gerbino, M., Paciello, M., \& Vecchio, G. M. (2006). Looking for adolescents' well-being: Self-efficacy beliefs as determinants of positive thinking and happiness. Epidemiologia e Psichiatria Sociale, 15(1), 30-43.

Cenkseven, F., \& Akbaş, T. (2007). Üniversite öğrencilerinde öznel ve psikolojik iyi olmanın yordayıcılarının belirlenmesi. Türk Psikolojik Danışma ve Rehberlik Dergisi, 27, 43-62.

Cicognani, E., Albanesi C., \& Zani, E. (2008). The impact of residential context on adolescents' subjective well being. Journal of Community \& Applied Social Psychology, 18, 558-575.

Çelik, Ş. (2008). Lise ögrencilerinin öznel iyi oluşlarının duygusal zekâ açısından incelenmesi (Yayımlanmamış yüksek lisans tezi). Selçuk Üniversitesi, Konya.

Çevik, N. (2010). Lise öğrencilerinin öznel iyi oluşlarını yordayan bazı değişkenler (Yayımlanmamış yüksek lisans tezi). Gazi Üniversitesi, Ankara.

Diener, E. (1984). Subjective well-being. Psychological Bulletin, 95, 542-575.

Diener, E., Emmons, R. A., Larsen, R. J., \& Griffin, S. (1985). The satisfaction with life scale. Journal of Personality Assessment, 49, 71-75.

Diener, E., Suh, E., Lucas, R. E., \& Smith, H. (1999). Subjective well-being: Three decades of progress. Psychological Bulletin, 125, 276-302.

Diener, E., Scollon, C. N., \& Lucas, R. E. (2004). The evolving concept of subjective well-being: The multifaceted nature of happiness. In P. T. Costa \& I. C. Siegler (Eds.), Advances in cell aging and gerontology (Vol. 15, pp. 187-220). Amsterdam: Elsevier.

Diener, E., Wirtz, D., Tov, W., Kim-Prieto, C., Choi, D-W., Oishi, S., \& BiswasDiener, R. (2010). New well-being measures: Short scales to assess flourishing and positive and negative feelings. Social Indicators Research, 97, 143-156.

Eryılmaz, A. (2010). Turkish adolescents' subjective well-being with respect to age, gender and SES of parents. International Journal of Human and Social Sciences, 5(8), 523-526.

Eryılmaz, A., \& Ercan, L. (2010). Öznel iyi oluş ile algılanan kontrol arasındaki ilişkinin incelenmesi. İlköğretim Online, 9(3), 952-959.

Eryılmaz, A., \& Ögülmüş, S. (2010). Ergenlikte öznel iyi oluş ve beş faktörlü kişilik modeli. Ahi Evran Üniversitesi Eğitim Fakültesi Dergisi, 11(3), 189-20.

Eryılmaz, A. (2012). Mental kontrol: Ergenler öznel iyi oluşlarını nasıl korurlar? Düşünen Adam Psikiyatri ve Nörolojik Bilimler Dergisi, 25, 27-34.

Garcia D., Rosenberg, P., Erlandsson A., \& Siddiqui, A. (2010). On lions and adolescents: Affective temperaments and the influence of negative stimuli on memory. Journal of Happiness Studies, 11, 477-495. 
Gupta, G., \& Kumar, S. (2010). Mental health in relation to emotional intelligence and self efficacy among college students. Journal of the Indian Academy of Applied Psychology, 36(1), 61-67.

Holder, M. D., \& Coleman, B. (2009). The contribution of social relationships to children’s happiness. Journal of Happiness Studies, 10, 329-349.

Huebner, E. S., \& Dew, T. (1996). The interrelationships of positive affect, negative affect, and life satisfaction in an adolescent sample. Social Indicators Research, 38, 129-137.

İkiz, E., \& Telef, B. B. (2013). The effects of socioeconomic status and gender besides the predictive effect of self-efficacy on life satisfaction in adolescence. International Journal of Social Science, 6(3), 1201-1216.

Karademas, E. C., Kafetsios, K., \& Sideridis, G. D. (2007). Optimism, self-efficacy and information processing of threat and well-being related stimuli. Stress and Health, 23, 285-294.

Karatzias, A., Chouliara, Z., Power, K., \& Vivien, S. (2006). Predicting general wellbeing from self-esteem and affectivity: An exploratory study with Scottish adolescents. Quality of Life Research, 15, 1143-1151.

Khodarahimi, S. (2010). General self-efficacy and worry in an Iranian adolescents and youths samples. Educational Research, 1(2), 15-20.

Köker, S. (1991). Normal ve sorunlu ergenlerin yaşam doyumu düzeylerinin karşılaştırılması (Yayımlanmamış yüksek lisans tezi). Ankara Üniversitesi, Ankara.

Long, R. F., Huebner, E. S., Wedell, D. H., \& Hills, K. J. (2012). Measuring schoolrelated subjective well-being in adolescents. American Journal of Orthopsychiatry, 82(1), 50-60.

Maddux, J. E. (2002). Self-efficacy: The power of believing you can. In C. R. Snyder \& S. J. Lopez (Eds.), Handbook of positive psychology (pp. 277-287). London: Oxford University Press.

Magaletta, P. R., \& Oliver, J. M. (1999). The hope construct, will, and ways: Their relations with self-efficacy, optimism, and general well-being. Journal of Clinical Psychology, 55(5), 539-551.

Marat, D. (2003). Assessing self-efficacy and agency of secondary school students in a multi-cultural context: Implications for academic achievement. Proceedings of the New Zealand and Australian Association for Research in Education Conference, 119.

Muris, P. (2001). A brief questionnaire for measuring self-efficacy in youths. Journal of Psychopathology and Behavioral Assessment, 23, 145-149.

Natvig, G. K., Albrektsen, G., \& Qvarnstrøm, U. (2003). Associations between psychosocial factors and happiness among school adolescents. International Journal of Nursing Practice, 9, 166-175. 
Özbay, Y., Palancı, M., Kandemir, M., \& Çakır, O. (2012). Üniversite öğrencilerinin öznel iyi oluşlarının duygusal düzenleme, mizah, sosyal öz-yeterlik ve başa çıkma davranışları ile yordanması. Türk Eğitim Bilimleri Dergisi, 10(2), 325-345.

Pasadashi, Z., Dehnavi, S. R., \& Botlani, S. (2012). The study of efficacy of cognitive therapy basis on positive psychology on subjective well- being. International Journal of Business and Social Science, 3(10), 202-207.

Singh, B., \& Udainiya, R. (2009). Self-efficacy and well-being of Adolescents. Journal of the Indian Academy of Applied Psychology, 35(2), 227-232.

Strobel, M., Tumasjan, A., \& Sporrle, M. (2011). Be yourself, believe in yourself, and be happy: Self-efficacy as a mediator between personality factors and subjective well-being. Scandinavian Journal of Psychology, 52, 43-48.

Suldo, S. M., \& Huebner, E. S. (2006). Is extremely high life satisfaction during adolescence advantageous? Social Indicators Research, 78, 179-203.

Telef, B. B. (2011). Olumlu ve olumsuz yaşantı ölçeğinin Türkçeye uyarlaması: Geçerlik ve güvenirlik çalışması. 11. Psikolojik Danışma ve Rehberlik Kongresi Bildiri Kitabl, 236-237.

Telef, B. B. (2011). Öz-yeterlikleri farkl ergenlerin psikolojik semptomlarının incelenmesi (Yayımlanmamış doktora tezi). Dokuz Eylül Üniversitesi, İzmir.

Telef, B. B. (2013). Olumlu ve olumsuz yaşantı ölçeği: Ergenler için geçerlik ve güvenirlik çalışması. Anadolu Psikiyatri Dergisi, 14, 62-68.

Tong, Y., \& Song, S., (2004). A study on general self-efficacy and subjective wellbeing of low SES-college students in a Chinese university. College Student Journal, 38, 637.

Willemse, M. (2008). Exploring the relationship between self-efficacy and aggression in a group of adolescents in the peri-urban town of Worcester (Unpublished master thesis). University of Stellenbosch, Stellenbosch, South Africa. 